\title{
Effect of Glycyrrhiza glabra extract on IVF outcome in Mice : Experimental model for mammals
}

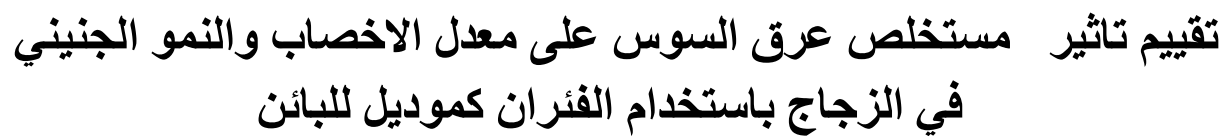

Saad, S. Al-Dujaily

Alaa S. Al-Saadi

Clinical Reproductive Physiology Dept. /IVF Institute/ Al-Nahrain University

\author{
الاء السعدي \\ سعد الاجيلي \\ معهد ابحاث الاجنة وعلاج العقم و مركز البحوث الطبية / كلية الطب ـجامعة النهرين
}

\begin{abstract}
Objective: To evaluate and examine the effect of Glycyrrhiza glabra extract (GgE) on the fertilization rate and embryonic development in vitro using the mice as a model for mammals. Design: Prospective study. Methods: Seven hundred forty ova were collected from superovulated ( SUO) females mice .Glycyrrhiza glabra extract was prepared and used for in vitro activation of caudal epididymal sperm . In vitro fertilization was performed using both $10 \%$ GgE mixed with IVF medium for 367 ova (treated group) and IVF medium alone for 373 ova(Control group) . Fertilization rate and normal development of different early embryonic cleavages stages was recorded. Results : There was a significant $(\mathbf{P}<0$.05) increase in the fertilization rate (FR ) of SUO mice oocytes $(53.89 \%)$ by using $10 \%$ GgE Compared to IVF medium alone in SUO group(36.82\%) . Addition of $10 \%$ GgE to the IVF medium, the number of 2-cell and 4-cell embryonic stages of SUO mice was significantly $(P<\mathbf{0 . 0 5})$ higher than that of control mice embryos cultured with IVF medium alone $(60 \%$ and $60 \%$ Vs. $51 \%$ and $54 \%$, respectively). Conclusion: The investigation showed that the Glycyrrhiza glabra extract may contain many growth factors, and energy sources that supporting the FR and normal development of early cleavage stages of mice embryos in vitro. This result can be utilized for IVF program in mammals.
\end{abstract}

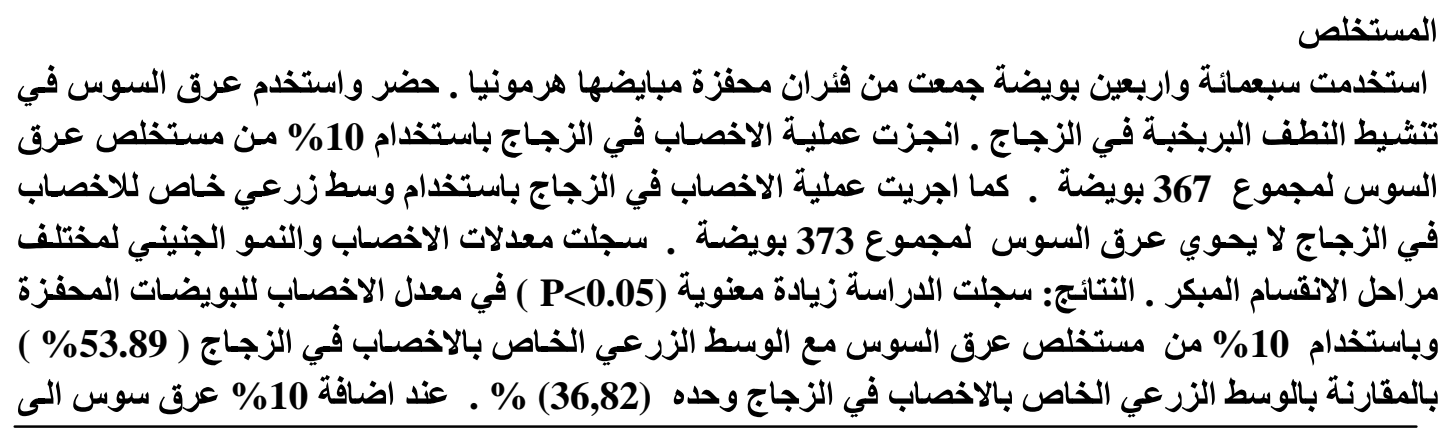

Keywords : Glycyrrhiza glabra, IVF, Fertilization rate, embryonic development in vitro 


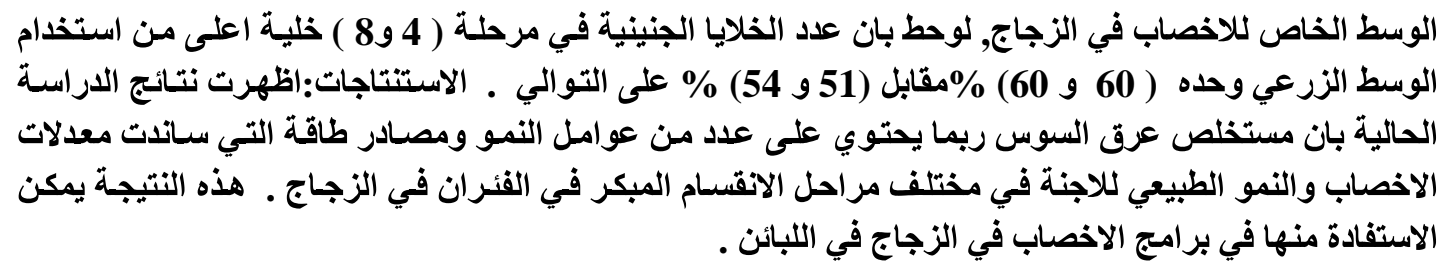

\section{Introduction}

In 1978, the first In vitro fertilization baby (Louise Brown) was born. Since that time, this procedure has been used with increased success rates to produce offspring from patients with various infertility problems. The birth of the first baby conceived in vitro, opened up a completely new frontier in treatment of infertility [1].

The indications for IVF were tubal factor infertility, which accounted for over $60 \%$ of cases in most series, followed by male factor infertility and combined tubal and male factors. Unexplained infertility and endometriosis were not so common indications and accounted for less than $20 \%$ of indications for IVF [2].

Over the following 25years, the pregnancy rates (PR) in IVF procedures have constantly improved and nowaday the success rates of around $20-30 \%$ per cycle are routinely reported by majority of Assisted Reproductive Techniques (ART) centers. Unfortunately, the need to increase the PR has lead to transfer of multiple embryos, resulting in unacceptably high $(\sim 30 \%)$ multiple pregnancy rate [3]. The potential adverse effects of multiple pregnancies have stressed the need to limit the number of embryos transferred in each cycle [4].

On the other hand, it has been found that many causes of infertility can be remedied simply by the correction of diet, and supplementation of vitamins and herbs [5] The medical use of herbal medications and nutritional supplements in their natural and unprocessed form undoubtedly began when noticed that certain food plants altered particular body functions, human culture institutionalized these observations, [6].

The medicinal use of Glycyrrhiza glabra (licorice) in both Western and Eastern cultures dates back several thousand years. Licorice is known to exhibit many pharmacological actions, such as estrogenic, anti testosterone, aldosterone-like; anti-inflammatory (cortisol-like); antiallergic; antibacterial, antiviral; and many others, [7]. Although much of the pharmacology focuses on glycyrrhizin and glycyrrhetinic acid; Licorice has many other components, such as flavonoids, that act as an antioxidant [8]. However, very limited information is mentioned in the literatures about the effect of Glycyrrhiza glabera on the fertilization rate of IVF and early embryonic development in human and animals. Therefore, the aim of the present study is to find out the effects of addition of $10 \% \mathrm{GgE}$ extract in the culture medium that used for IVF on In vitro Fertilization rate (FR) and In vitro preimplantation embryonic development (ED) using the mice as an experimental model for mammals.

\section{Materials and Methods}

\section{Management of experimental animals:}

Males and females mature Balb /C mice 8-12 weeks old and 25-30 gm of weight were obtained from the Animal House of the Institute of Embryo Researches and Infertility 
Treatment/ Al-Nahrain University. They were kept in an air conditioned room $\left(\sim 25^{\circ} \mathrm{C}\right)$ with a photoperiod $(13 \pm 2)$ hours. The animals were housed in box cages of opaque plastic measuring $(29 \times 15 \times 12) \mathrm{cm}$. Tap water and diet were freely available for the animals (ad libitum ) [9].

\section{Glycyrrhiza glabra preparation:}

The extract was provided as a water soluble powder form (Food Industry Company Iraq). Storage of Glycyrrhiza was done in well-closed container protected from light and moisture [10].

Glycyrrhiza glabra extract was used for the treatment groups as $10 \%$ concentration, was prepared by adding $0.1 \mathrm{ml}$ of $\mathrm{Gg}$ suspension $(0.1 \%$ the stock solution $)$ to $0.9 \mathrm{ml}$ of mouse IVF media (HTF, Millipore, USA and KSOM-AA Millipor). The $10 \%$ solution was filtered by using millipore size $0.45 \mu \mathrm{m}$ and $0.22 \mu \mathrm{m}$ (Millipore) and then $\mathrm{pH}$ was adjusted to reach 7.2-7.4.using $\mathrm{pH}$ meter.

\section{Preparations before in vitro fertilization}

- Male vasectomy: The mature male mice were vasectomized as the procedure was described by [11].

- Detection of female estrous cycle: Stages of the mice estrous cycle were detected and reported using vaginal smears. The smears were performed daily between 8:00 am and 1:00 pm. The procedure was done according to [9].

-Superovulation induction: Superovulation was induced by intra peritoneal injection of 7.5 IU of pregnant mare serum gonadotropin (PMSG, Folligon ${ }^{\circledR}$, Holland), then followed by IP injection of $7.5 \mathrm{IU}$ of human chorionic gonadotropin (hCG, Pregnyl ${ }^{\circledR}$, China) after 42-48 hours. Ovulation was taken place between $12 \pm 2$ hours after injection of hCG, then after 5 hours of hCG injection, one vasectomized male mouse was placed with three superovulated female mice to enhance ovulation induction procedure, [9].

The number of collected oocytes that cultured for one hour before IVF program in GgE free HTF medium was 367 oocytes (the control). Whereas, the number of collected oocytes that cultured for one hour before IVF in 10\%G.g-HTF medium was 373 oocytes (the treated group).

-One day before IVF procedure: Sperms and oocytes collection and culture dishes were prepared as the following:

A. Epididymal sperm and Egg collection dishes: central well Falcon culture dishes were contained $1 \mathrm{ml}$ of GgE-free HTF medium for the control group and another dishes contained 10\% GgE-HTF medium for the treatment group.

B. Microdrops Culture Dishes Preparation: Drops of culture media (in two groups: GgE-free HTF medium and $10 \%$ GgE-HTF medium) were dispensed in an array on the bottom of $35-\mathrm{mm}$ sterile plastic tissue culture dishes. The dishes were flooded with embryo-tested light mineral oil.

C. Fertilization dishes: Were contained $250 \mu \mathrm{l}$ of GgE-free HTF medium for the control group and another dishes contained $10 \%$ GgE-HTF medium for the treated group. Culture dishes (1 per each fertilization dish): Were contained 5 drops $\mathrm{x}$ $100 \mu 1$ of GgE-free KSOM-AA medium for the control group and another dishes contained $10 \%$ GgE- KSOM-AA medium for the treated group in a 35-mm dish 
also. The dishes were transferred to an incubator at $37^{\circ} \mathrm{C}$ in an atmosphere of $5 \%$ $\mathrm{CO}^{2}$ and $100 \%$ humidity.

\section{IVF procedure:}

-Mature male mouse was sacrificed by cervical dislocation. The caudal epididymis region was isolated and put in previously prepared $1 \mathrm{ml}$ of HTF medium in a central well Falcon culture dishes [11].

All treated and control epididymal sperms were obtained and evaluated under the high power of light microscope to determine the final sperm concentration, motility and morphology before insemination as described by Alsaadi, [12].

- In vitro Fertilization: A mature female mouse was sacrificed by cervical dislocation at 13 hours post-hCG administration. The oviducts were dissected out and placed them into a culture dish contain $1 \mathrm{ml}$ of oocyte collection medium with the aid of dissecting microscope. All the cumulus masses were transferred to a single fertilization dish. After one hour of incubation, sperm was gently added to each fertilization dish by using a widebore pipette tips to give a final motile sperm concentration of $1 \times 10^{6} \mathrm{ml}$. Fertilization dishes were Incubate at $37^{\circ} \mathrm{C}, 5 \% \mathrm{CO}_{2}$ and $100 \%$ humidity. After four to six hours of insemination, oocytes were washed through several drops of HTF medium "in wash dish" to remove the excess of sperm and debris. The washed fertilized oocytes incubated overnight in $100 \mu \mathrm{l}$ fresh HTF microdrops under mineral oil. The culture medium KSOMAA was used for the culture of developing embryos [11, 13].

Fertilization rate was assessed by recording the number of zygote and two cells stage embryos 6-12 hours after insemination in vitro. Early embryo morphological evaluation was assessed on warmed microscopic stage of a Wild inverted microscope. Early embryos with 2 to 8 blastomeres were evaluated morphologically according to, [14].

All statistical analysis was performed with SPSS statistical program, LEAD Technologies. Results were expressed as mean \pm SEM and analyzed using paired sample t-test and Chisquare test depending on the nature of the data. When P-value reach the degree of 0.05 , it was considered significant [15].

\section{Results}

\section{-In vitro activation technique:}

In table 1 , the mean sperm concentration $\left(\times 10^{6} \mathrm{sperm} / \mathrm{ml}\right)$ following direct activation with $10 \%$ GgE-HTF medium was significantly $(\mathrm{P}<0.05)$ higher than before activation. Active sperm motility (grade A and grade $\mathrm{B}$ ) was significantly $(\mathrm{P}<0.05)$ increased compared with before activation. The percentage of morphologically normal sperms following the addition of $10 \%$ GgE-HTF medium showed no significant $(\mathrm{P}>0.05)$ difference when compared with the GgE-free HTF medium.

\section{- Fertilization rate: (FR)}

Fertilization rate was gained by dividing the numbers of preimplantation embryos after 24 hours after insemination on the number of collected oocytes. The FR in control groups was $36.82 \%$ (134 embryos out of 367 oocytes), While the FR in treated groups was $53.89 \%$ (200 embryos out of 373 oocytes). There was a highly significant $(\mathrm{P}<0.001)$ difference between the two groups, as shown in table- 2 . 


\section{-Embryonic developments after $24 \mathrm{hrs}$ and $48 \mathrm{hrs}$}

This study was concerned on the numbers of mouse preimplantation embryo development after 24 and 48 hours of insemination and on the percentage of normal embryonic developments. There were 134 embryos after 24 hours of insemination and incubation with GgE-free HTF culture medium (control group), the stages of embryonic developments was 69 embryos at two cells stage and 65 embryos at three-four cells stage. While after the same period of insemination and incubation with $10 \%$ GgE-HTF culture media (treated group), there was 200 embryos divided into 119 embryos at two cells stage and $81 \mathrm{embryos}$ at three-four cells stage. There was a highly significant $(\mathrm{P}<0.001)$ difference in the total number of embryos and at the total number of two cells stage of embryos after 24 hrs as shown in table (2).

There were 134 embryos after 48 hours following insemination and incubation with GgEfree KSOM-AA culture medium (control), the stages of embryonic developments were 36 embryos at two cells stage, 72 embryos three-four cells stage and 26 embryos at five-eight cells stage. While after the same period of insemination and incubation with $10 \% \mathrm{GgE}$ KSOM-AA culture media (treated groups), there was a (200) embryos divided into 30 embryos at two cells stage, 121 embryos at three-four cells stage and 49 embryos at fiveeight cells stage. And there was a highly significant $(\mathrm{P}<0.001)$ difference at the total number of embryos and at the total number of three-four cell stage and five-eight of embryos after $48 \mathrm{hrs}$ as shown in table( 3 ).

Table (1): Comparison between the effect of addition of G.g-free HTF medium and $10 \%$

\begin{tabular}{|c|c|c|c|}
\hline & & \multicolumn{2}{|c|}{ In vitro activation } \\
\hline \multicolumn{2}{|l|}{ Grouping with and without G.g. } & $\begin{array}{c}\text { After one hour } \\
\text { incubation }\end{array}$ & Significance \\
\hline \multirow{2}{*}{ Sperm concentration $\left(10^{6} / \mathrm{ml}\right)$} & Without G.g & $24.36 \pm 1.405$ & \multirow{2}{*}{0.039} \\
\hline & With G.g & $34.33 \pm 4.323$ & \\
\hline \multirow{2}{*}{ Sperm motility grade A (\%) } & Without G.g & $11.40 \pm 2.315$ & \multirow{2}{*}{0.046} \\
\hline & With G.g & $19.73 \pm 0.918$ & \\
\hline \multirow{2}{*}{ Sperm motility grade B (\%) } & Without G.g & $21.33 \pm 2.622$ & \multirow{2}{*}{0.042} \\
\hline & With G.g & $29.73 \pm 2.472$ & \\
\hline \multirow{2}{*}{ Progressive motility $(\mathrm{A}+\mathrm{B}) \%$} & Without G.g & $32.73 \pm 4.362$ & \multirow{2}{*}{0.022} \\
\hline & With G.g & $49.46 \pm 3.065$ & \\
\hline \multirow{2}{*}{ Morphologically normal sperms $\quad(\%)$} & Without G.g & $69.43 \pm 4.410$ & \multirow{2}{*}{0.741} \\
\hline & With G.g & $70.93 \pm 3.084$ & \\
\hline
\end{tabular}

G.g-HTF medium on certain sperm function parameters following in vitro direct activation.

.Values are Mean \pm SEM

$\mathbf{P}<0.05$ is significant 
Table (2): Comparison in fertilization rate and embryonic development between GgE-free HTF medium (control group) and $10 \%$ G.g-HTF medium (treated group) after 24 hours of insemination

\begin{tabular}{|c|c|c|c|}
\hline \multicolumn{2}{|c|}{ Grouping with and without G.g. } & Fertilization & Significance \\
\hline \multirow{2}{*}{$\begin{array}{l}\text { Total number of fertilized oocytes } \\
\text { after } 24 \mathrm{hrs}\end{array}$} & Without G.g & $134 / 367(36.82)$ & \multirow[b]{2}{*}{0.001} \\
\hline & With G.g & 200/373 (53.89) & \\
\hline \multicolumn{2}{|c|}{ Grouping with and without G.g. } & $\begin{array}{c}\text { Embryonic } \\
\text { development rate }(\%)\end{array}$ & Significance \\
\hline \multirow{2}{*}{$\begin{array}{c}\text { Total number of two cells stage of } \\
\text { embryo after } 24 \mathrm{hrs}\end{array}$} & Without G.g & $69 / 134(51.5)$ & \multirow{2}{*}{0.001} \\
\hline & With G.g & $119 / 200(60)$ & \\
\hline \multirow{2}{*}{$\begin{array}{c}\text { Total number of } 3 \text { - } 4 \text { cells stage of } \\
\text { embryo after } 24 \mathrm{hrs}\end{array}$} & Without G.g & $65 / 134(48.5)$ & \multirow{2}{*}{0.082} \\
\hline & With G.g & $81 / 200(40)$ & \\
\hline
\end{tabular}

Table (3): Comparison in embryonic development between GgE-free KSOM-AA medium (control group) and 10\% G.g-Ksom-AA medium (treated group) after $48 \mathrm{hrs}$. of insemination.

\begin{tabular}{|c|c|c|c|}
\hline \multicolumn{2}{|c|}{ Grouping with and without G.g. } & $\begin{array}{c}\text { Total embryonic } \\
\text { development rate } \\
(\%)\end{array}$ & \multirow{2}{*}{ Significance } \\
\hline \multirow{2}{*}{ Total number of embryos after 48 hrs } & Without G.g & $134 / 367(36.82)$ & \multirow{2}{*}{0.001} \\
\cline { 2 - 3 } & With G.g & $200 / 373(53.89)$ & \multirow{2}{*}{0.302} \\
\hline $\begin{array}{c}\text { Number of total two cells stage } \\
\text { embryos after } 48 \text { hours }\end{array}$ & Without G.g & $36 / 134(27)$ & \multirow{2}{*}{0.001} \\
\cline { 2 - 3 } $\begin{array}{c}\text { Total number of } 3-4 \text { cells stage of } \\
\text { embryos after } 48 \text { hrs }\end{array}$ & With G.g & $30 / 200(15)$ & \multirow{2}{*}{0.001} \\
\cline { 2 - 3 } $\begin{array}{c}\text { Total number of 5 - 8 cells stage of } \\
\text { embryos after } 48 \text { hrs }\end{array}$ & With G.g & $121 / 200(60)$ & \\
\cline { 2 - 3 } & Without G.g & $26 / 134(19)$ & \\
\hline
\end{tabular}

\section{Discussion}

\section{1. -In vitro sperm direct activation:}

In this study, there was an enhancement in certain sperm function parameters following in vitro activation by adding $\mathrm{GgE}$ to the culture medium used, and that was attributed firstly to the direct activation technique with HTF medium. The medium provided the same culture components which found in the female genital tract and that will trigger the sperm hyperactivity motility [11]. Secondly, adding of $\mathrm{GgE}$ to the culture media enhances different sperm function parameters following 60 minutes of activation, namely; sperm concentration, total sperm motility percentage and grade activity of forward progressive movement. And the booster effect of GgE powder extract on epididymal sperms to move 
out and to release from the epididymal tissue. Glycyrrhiza glabra has an estrogenic activity due to the presence of glabridin which is known to be a phytoestrogenic and has the ability to bind to human estrogen receptors [16]. Estrogens are known to improve sperm characteristics including sperm motility and grade activity in addition to induction of hyperactive motility [17]. Moreover, it has been found that the G.g contains $\mathrm{Ca}^{+2}$, potassium, glucose, fructose, vitamin $\mathrm{E}$, vitamin $\mathrm{C}$ and many other substances e.g.: $\mathrm{Zn}^{+2}$, sucrose, amino acid[7], all these substances stimulate sperm motility and the grade activity of forward movement. The sugars are considered to be a source of energy for sperm motility, the protein and amino acids, which sustain and maintain sperm osmolarity and in turn integrity of sperm cell membrane [18].

\section{Fertilization rate:}

The results of this study showed a significant increase in the FR after 24 hours of insemination, and the differences in the means are $17 \%$ between the treated and control groups. Several factors may affects the FR in the present work. First, all the ovulated oocytes are inseminated with the same sperm concentration $\left(1 \times 10^{6} \mathrm{sperm} / \mathrm{ml}\right)$. Therefore, the differences in FR are not due to the increments in the sperm concentration but it may be belonged to the effect of the direct activation technique with $10 \% \mathrm{GgE}$ and to the decrease in the insemination volume to each fertilization well. This reduction may reduce the decapacitation factors and contaminants from the seminal plasma [19].

The study found that the FR increases with an increasing in sperm motility and grade activity of progressive forward movement. This finding is in agreement with [20], who emphasized that the only parameter that could predict treatment outcome was the percentage of motile spermatozoa after appropriate sperm preparation. The last factor that may interfere with the increases in FR was the addition of GgE powder extract to the insemination medium. The GgE extract provided a wide range of active ingredients that provide a nourishment and/or protection to the oocytes and early cleaved embryos. The licorice contains antioxidant compounds like: isoflavones, hispaglabridin $\mathrm{A}$ and $\mathrm{B}$, which inhibit $\mathrm{Fe}^{+3}$ induced mitochondrial lipid peroxidation [21].

\section{Embryonic developments:}

A significant improvement in ED and in embryo quality was observed after 24 of insemination with $10 \% \mathrm{Gg}-\mathrm{HTF}$ medium. This improvement can be attributed to the addition of $10 \% \mathrm{GgE}$ with HTF and KSOM-AA medium, because all variables during the insemination and culture procedures were fixed and controlled. The positive effects of $\mathrm{GgE}$ that recognized in this study may be augmented by a number of active ingredients like: Ascorbic-acid, Asparagine, Carotenes, Fructose, Glucose, Magnesium, Maltose, Manganese, Sucrose, Sugar, Thiamin, Vitamin E etc., each of which have different effects on oocytes and early developed embryos [7]. Moreover, GgE contains Glycyrrhizin $(10 \%)$ as calcium and potassium salts of glycyrrhizic acid. Therefore, in the present study, the first cleavage and development of early developed embryos occur in a wide range of sodium, magnesium, calcium, and potassium concentrations[22]. It may also be explained the developing embryo is exposed to gradients of carbohydrates as it develops, together with amino acids. It has been noticed that carbohydrates are the main energy substrates for the embryo[23]. The plant is rich in glucose and the addition of GgE extract to HTF 
medium enhanced the EDs after 24 hours of insemination. That may be explained that the mice cumulus cells surrounding the oocyte and early embryo readily produce both pyruvate and lactate from glucose [24]; whilst glucose uptake increases with development[25].

At this work, there was early developmental arrest of mouse embryos. This finding may be associated with elevated levels of free oxygen radicals, indicating that oxidative stress might be the reason for such high incidence of arrest [26]. Oxidative stress may be generated endogenously or exogenously, but either way it can affect the oocyte and embryo. Therefore, IVF culture media, may be the exogenous site of oxidative stress generation ,affecting the oocytes and the preimplantation embryo [27]. Higher day one ROS levels in culture media were associated with delayed embryonic development [28], high fragmentation and development of morphologically abnormal embryo after prolonged culture. In treated group, the antioxidant system is influenced GgE powder extract which contains a wide range of vitamins and minerals such as vitamin $\mathrm{C}$, vitamin $\mathrm{E}$, selenium, zinc, taurine, hypotaurine, glutathione, beta carotene, and carotene which may play a critical role in conversion of ROS to $\mathrm{H} 2 \mathrm{O}[29,30]$. Vitamin $\mathrm{C}$ and vitamin $\mathrm{E}$ is a chain breaking antioxidant that stops the propagation of the peroxidative process. Thus, treatment with $10 \% \mathrm{GgE}$ increased the total antioxidant capacity in culture media of oocytes that later were successfully fertilized.

It is concluded from the present study that the addition of $\mathrm{GgE}$ to the culture media of sperm and oocyte can enhance the fertilization rate and embryonic development in mice. This result can be utilized for other mammalian IVF programs.

\section{References}

1. Steptoe, P. C. and Edwards, R. G.: Birth after the preimplantation of a human embryo. Lancet. 2: 366. 1978.

2. Giwa-osagie, O.F. ART in developing countries with particular reference to subSaharan Africa. In: Vayena, E.; Rowe, P. J. and Griffin, P. D. (Eds.): Current Practices and Controversies in Assisted Reproduction. WHO Headquarters. Geneva. Pp: 177209. 2002

3. Nygren, K. G. and Andersen, A. N. Assisted reproductive technology in Europe, 1999. Results generated from European registers by ESHRE. Human Reproduction. 17: 3260-3274. 2002.

4. Bergh, T.; Ericson, A. and Hillensjo, T. Deliveries and childrenborn after in vitro fertilisation in Sweden 1982-95: a retrospective cohort study. Lancet. 354: 1579-1585. 1999.

5. Johnston, L. Herbal Medicine for Physical Disability. Available from: http://Www.healingtherapies.info/herbal.htm! 2005.

6. Dennehy, C.E. and Tsourounis, C. Botanicals "Herbal Medications" and Natural supplements. In: Katzung, B.G. (Eds.): Basic and Clinical Pharmacology. 9th Edition. MacGraw-Hill. Pp: 1530-1531. 2004.

7. Taylor, L. (2004): Database File for Licorice. Raintree Nutrition Inc. Available from http://WwW.rain-tree.com/licorice.htmi. 
8. Blumenthal, M. and Klein, S. German Bundesgesuntheitsamt (BGA) Commission E Therapeutic Monographs on Medicinal Products for Human Use. (English translation). American Botanical Council. Austin. Texas. Pp: 223-229. 1996.

9. Al-Dujaily, S.S. In Vitro Sperm Activation and Intra-bursal Insemination in Mice. Ph.D. thesis. College of veterinary medicine. Baghdad University. Pp: 60-90. 1996

10. Mohammed, M.N. The effect of addition of Glycyrrhiza glabera crude extract on in vitro human sperm activation of infertile patients . M. Sc. thesis. Institute of Embryo Research and Infertility Treatment. Baghdad University. Pp: 72. 2003

11. Nagy, A.; Gertsenstein, M.; Vintersten, K. and Behringer, R. Manipulating the Mouse Embryo, A Laboratory Manual. 3rd Edition. Cold Springer Harbor Press. New York. Pp: 31-61. 2003

12. Alsaadi,A.Sh.The Effect of Glycyrrhiza glabra on the IVF in Mice. MSc. Thesis. IVF Institute, Al-Nahrain University. 2008.

13. Lane, M. and Gardner, D.K. preparation of gametes, in vitro maturation, in vitro fertilization, and embryo recovery and transfer. Gardner, D.K.; Lane, M. and Watson, A.J. (Eds.) In: A Laboratory Guide to the Mammalian Embryo. Oxford University Press. Oxford. Pp: 24-41. 2003

14. Hartshorne,G.M.Embryo.Human Reproduction ,15(4):101-111,2000.

15. Sorlie, D.E .Medical biostatistics: Examination and board review. Norwalk. Connecticut. Appleton and lang. Pp: 47-88. 1995.

16. Tamir, S.; Eizenberg, M.; Songen, D.M.; Shelach, R.; Kaye, A. and Vaya, J. Estrogenic and Anti-proliferative Properties of Glabridin from Licorice in Human Breast Cancer cells. Cancer Research. 15(60): 5704. 2000.

17. AL-Jarah, I.A.N. Study of the Some Exogenous Hormones on Sperm in vitro Activation of Asthenozoospermia Patients. MS.c Thesis. College Science. University of Babylon. 2002.

18. AL-Dujaily, S.S.; AL-Janabi, A.S. and Nori, M. Effect of Glycyrrhiza extract on in vitro sperm activation of asthenospermic patients. J . Babylon University. 11(3): 477483. 2006.

19. Jeyendran, R. S. and Zhang, X. J. Sperm processing methods. In:Jeyendran R. S. (Ed.): Sperm Collection and Processing Methods: A Practical Guide. Cambridge University press. Pp: 107-110. 2003

20. Kasai, T.; Ogawa, K. and Mizuno, K. Relationship between sperm mitochondrial potential, sperm motility and fertility potential. Asian Journal of Andrology. 4: 97-103. 2002.

21. Haraguchi, H.; Yoshida, N.; Ishikawa, H.; Tamura, Y.; Mizutani, K. and Kinoshita, T. Protection of mitochondrial functions against oxidative stresses by isoflavones from Glycyrrhiza glabra. Journal of pharmacy and pharmacology. 52: 219-223. 2000.

22. McKiernan, S.H. and Bavister, B.D. Environmental variables influencing in vitro development of hamster 2-cell embryos to the blastocyst stage. Biology of Reproduction. 43:404. 1990.

23. Lane, M. and Gardner, D. K. Embryo Culture Systems In: Gardner ,D. K. (Ed): In vitro Fertilization A Practical Approach. Informa Healthcare. New York. Pp: 221. 2007. 
24. Gardner, D.K. and Leese, H.J. Concentrations of nutrients in mouse oviduct fluid And their effects on embryo development and metabolism in vitro.Journal of Reproduction and Fertility. 88: 361-368.1990.

25. Gardner, D.K.; Lane, M.; Stevens , J. and Schoolcraft, W.B. Non invasive assessment of human nutrient consumption as a measure of developmental potential. Fertility Sterility. 76:1175. 2001.

26. Agarwal, A.; Gupta, S. and Sharma, R. K. Role of oxidative stress in female reproduction Reprod. Biol. Endocrinol. 3:28, 2005.

27. Harvey, A.J.; Kind, K.L. and Thompson, J.G. REDOX regulation of early embryo development. Reproduction. 123:479-486. 2002.

28. Bedaiwy, M.A.; Falcone, T.; Mohamed, M.S.; Aleem, A.A.; Sharma, R.K.;Worley, S.E.; Thornton, J. and Agarwal, A. Differential growth of human embryos in vitro: role of reactive oxygen species. Fertility and Sterility. 82:593-600. 2004.

29. Van Langendonckt, A.; Casanas-Roux, F. and Donnez, J. Oxidativestress and peritoneal endometriosis. Fertility and Sterility. 77:861-870. 2002.

30. Agarwal, A.; Saleh, R.A. and Bedaiwy; M.A. Role of reactive oxygen species in the pathophysiology of human reproduction. Fertility and Sterility. 79:829-843. 2003. 